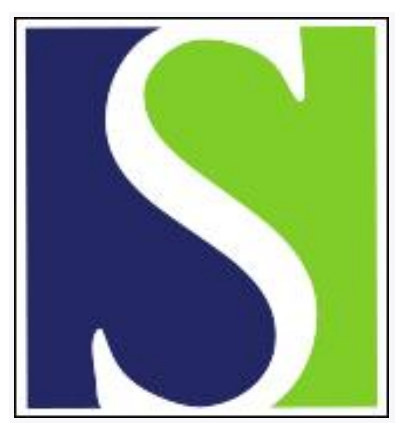

Scand J Work Environ Health 1986;12(1):16-21

https://doi.org/10.5271/sjweh.2179

Issue date: Feb 1986

A cohort mortality study of painters and allied tradesmen.

by Matanoski GM, Stockwell HG, Diamond EL, Haring-Sweeney M, Joffe $\mathrm{RD}$, Mele LM, Johnson ML

This article in PubMed: www.ncbi.nlm.nih.gov/pubmed/3961437

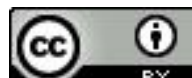




\title{
A cohort mortality study of painters and allied tradesmen
}

\author{
by Genevieve M Matanoski, MD, DPH, ${ }^{1}$ Heather G Stockwell, ScD, ${ }^{1,2}$ Earl L Diamond, PhD, ${ }^{1}$ \\ Marie Haring-Sweeney, MPH, ${ }^{3}$ Richard D Joffe, MA, ${ }^{1}$ Lisa M Mele, ScM,${ }^{1,4}$ Martha L Johnson, MHS ${ }^{1}$
}

\begin{abstract}
MATANOSKI GM, STOCKWELL HG, DIAMOND EL, HARING-SWEENEY M, JOFFE RD, JOHNSON ML. A cohort mortality study of painters and allied tradesmen. Scand J Work Environ Health 12 (1986) 16-21. A cohort study was conducted of the membership of a large international union of painters and allied tradesmen. The union membership consisted of both painters and associated trades such as glaziers and tile and carpet layers. The study examined the mortality experience of 57175 current and former union members in four states (California, Missouri, New York, and Texas) in the United States (US) from 1975 through 1979. No excess mortality was observed for the total union membership when compared to that of all US white males. When the study population was subdivided by the trade affiliation, members of locals comprised primarily of painters exhibited a significant elevation in mortality from all malignant neoplasms, lung cancer, and stomach cancer, compared to all US white males. To reduce the impact of potential nonoccupational differences between the study population and all US white males, the data were also analyzed using the entire cohort as the standardization population. Significant elevations continued to be observed for all malignant neoplasms and lung cancer among the membership of painting locals compared to other locals. In addition there was a statistically significant difference in mortality from leukemia and cancer of the bladder observed between the groups.
\end{abstract}

Key terms: lung cancer, painting, stomach cancer.

In 1977 The Johns Hopkins University initiated a study of the health hazards associated with work in the construction and maintenance painting trades. Occupational exposures experienced by these painters may include a variety of solvents, pigments, and paint additives, as well as spackling and similar compounds. Few epidemiologic studies have been conducted on the mortality experience of construction or maintenance painters. The occupational tables of the Registrar General for England and Wales $(13,14)$, two national mortality studies $(7,18)$, and studies in several states $(5,6,9$, $19,20,21)$ have suggested elevated mortality ratios from cancers of several sites including the lung $(7,9$, $13,14,18)$, larynx (7), esophagus (20), and stomach (20), as well as leukemias $(19,21)$, among painters. The use of chromate primers has been associated with an elevated lung cancer risk in some industry settings (3, $4,8)$, but not in others $(2,11,12)$.

Construction and maintenance painters were chosen as the focus of the epidemiologic study. These painters comprise approximately $70 \%$ of all painters in the

1 Department of Epidemiology, The Johns Hopkins University School of Hygiene and Public Health, Baltimore, Maryland 21205, United States.

2 Currently: College of Public Health, University of South Florida, Tampa, Florida 33612, United States.

${ }^{3}$ National Institute for Occupational Safety and Health, Cincinnati, Ohio, United States.

4 Currently: International Center for Epidemiologic and Preventive Opthamology, The John Hopkins University, Baitimore, Maryland 21205, United States.

Reprint requests to: Dr HG Stockwell, College of Public Health, University of South Florida, 13301 N 30th Street, Tampa, FL 33612, USA.
United States (US) (16). Construction painters typically move from one worksite to another, and this movement makes it difficult to identify a centralized source of employment data. The construction trades, including painting, have traditionally been unionized trades. The membership records of the International Brotherhood of Painters and Allied Trades (IBPAT) provided an effective mechanism for identifying a large painter cohort for epidemiologic study.

This union, with a current membership of approximately 200000 , represents most unionized construction and maintenance painters in the United States. Painters comprise approximately $60 \%$ of the membership, and a number of allied trades the remaining $40 \%$. Each local is classified by the Union as either "mixed," consisting primarily or exclusively of painters, or is designated as a specific allied trade (table 1).

\section{Material and methods}

A nonconcurrent prospective study was undertaken to determine whether members of this union were experiencing any excess mortality when compared to all US white males. The study also evaluated whether significant differences existed in the mortality experience of construction and maintenance painters within the Union in comparison to that of allied trade members.

The Union membership in the four states of California, Missouri, New York, and Texas was selected for study. The Union provided the study investigators with computerized listings of its current, retired, and terminated members. These membership files identified the specialty affiliation of each local union and indi- 
cated the local to which a member belonged, but did not indicate the trade of individual members. All comparisons were therefore necessarily made by type of local affiliation of each member. Social security numbers, necessary for vital status ascertainment, were available only for recent years. For this reason, a fiveyear follow-up period was selected.

The eligible study population consisted of Union members who were born prior to 1940 , who had at least one full year of Union membership, and who had been a Union member in one of the four states during 1975 - 1979. Deaths within the study population were ascertained for 1975-1979 through a search of the life insurance files of the Union, the records of the Social Security Administration, the National Death Index, the Veteran's Administration, and the Health Care Financing Administration. Death certificates were coded in the eighth revision of the International Classification of Diseases Adapted (ICDA-8). Standardized mortality ratios and proportional mortality ratios were calculated for the cohort on the basis of mortality rates for all US white males with the program developed by R Monson (10).

Information on the race and sex composition of the study population was not available from Union records. As first initial only was recorded in the Union file, first name could not be used to identify female cohort members. Based on a review of all death certificates of cohort members, $99.5 \%$ were male and $98 \%$ white. The entire cohort was considered as white males in the estimation of the rates. Deaths among female cohort members were excluded from the analysis, and therefore the total number of deaths was decreased by 26 .

\section{Results}

The study cohort consisted of 57175 individuals who contributed 257221.5 person-years of observation. Since the study excluded anyone who was a member of the Union for less than one year, the first year of membership was discounted for all individuals. During the study period $22 \%(\mathrm{~N}=12628)$ of the members left the Union. All others remained in the Union as either active or retired members. Individuals lost to follow-up during the study period numbered 1271 $(2.2 \%)$. All lost to follow-up were considered alive for purposes of analysis. Thirty-one additional individuals were omitted from the cohort for the calculation of the standardized mortality ratio (SMR) and proportionate mortality ratio (PMR), as specified by the Monson program, as their ages were 100 years or greater. The distribution of ages of the cohort at the start of the study are indicated in table 2. Among the cohort members, 5313 deaths occurred. Death certificates listing cause of death were obtained for all but 288 deceased individuals $(5.4 \%)$.

Mortality from all causes of death was $88 \%$ of that predicted based on the death rates for all US white
Table 1. Local affiliation of cohort members.

\begin{tabular}{lcc}
\hline Local & $\begin{array}{c}\text { Number } \\
\text { in cohort }\end{array}$ & $\begin{array}{c}\text { Percentage } \\
\text { of cohort }\end{array}$ \\
\hline Mixed (painting) & 33098 & 57.9 \\
Glaziers, glass workers & 4941 & 8.7 \\
Sign writers & 3694 & 6.5 \\
Tile and carpet layers & 3480 & 6.1 \\
Paint makers & 2413 & 4.2 \\
Industrial workers & 1648 & 2.9 \\
Wood finishers & 1184 & 2.1 \\
Warehouse workers & 1088 & 1.9 \\
All other & 5606 & 9.7 \\
\hline Total & 57152 & 100.0 \\
\hline
\end{tabular}

Table 2. Distribution of ages of cohort members at the start of the study.

\begin{tabular}{lccc}
\hline Age group & Cohort size & $\begin{array}{c}\text { Percentage } \\
\text { of cohort }\end{array}$ & Person-years \\
\hline $35-39$ & 8271 & 14.5 & 19826.1 \\
$40-44$ & 8492 & 14.9 & 38800.0 \\
$45-49$ & 8158 & 14.3 & 36677.0 \\
$50-54$ & 7750 & 13.5 & 36215.6 \\
$55-59$ & 6773 & 11.8 & 33291.7 \\
$60-64$ & 5896 & 10.3 & 29394.7 \\
$65-69$ & 4795 & 8.4 & 24399.8 \\
$70-74$ & 3415 & 6.0 & 18409.9 \\
$75-79$ & 1997 & 3.5 & 11169.4 \\
$\geq 80$ & 1628 & 2.8 & 9037.9 \\
\hline Total & 57175 & 100.0 & 257221.5 \\
\hline
\end{tabular}

males (table 3). This deficit was due primarily to low rates for all circulatory diseases (except rheumatic heart disease). An unexpected finding was the low rate of all accidents (SMR $=78)$ and motor vehicle accidents (SMR $=76$ ). Mortality was also lower than expected from diseases of the digestive system $(\mathrm{SMR}=83)$ and the nervous system $(\mathrm{SMR}=58)$. In contrast, many ratios for specific cancer sites were at or above the expected mortality for the general population.

Proportional mortality ratios were also calculated to compare the distribution of causes of death in this population to that of all US white males. The results of the analysis are shown in table 4. The distribution of causes of death experienced by this study population differed from that of the general male population. The analysis indicated that in the study population there was a statistically significant excess of all malignant neoplasms and a number of specific cancer sites. The proportionate mortality ratios were significantly elevated for cancers of the stomach, large intestine, liver, lung, and kidney. That of cancer of the brain was significantly low. No other specific causes of death except cancers showed a significant excess. Mortality from diseases of the circulatory system was lower than expected.

The study cohort was then subdivided by local affiliation, as either painter or allied trade. There were 33098 members of mixed locals and 24054 members of one of the allied trade locals in the study. Twenty- 
Table 3. Standardized mortality ratios (SMR) for selected causes of death among the total study membership, 1975-1979.

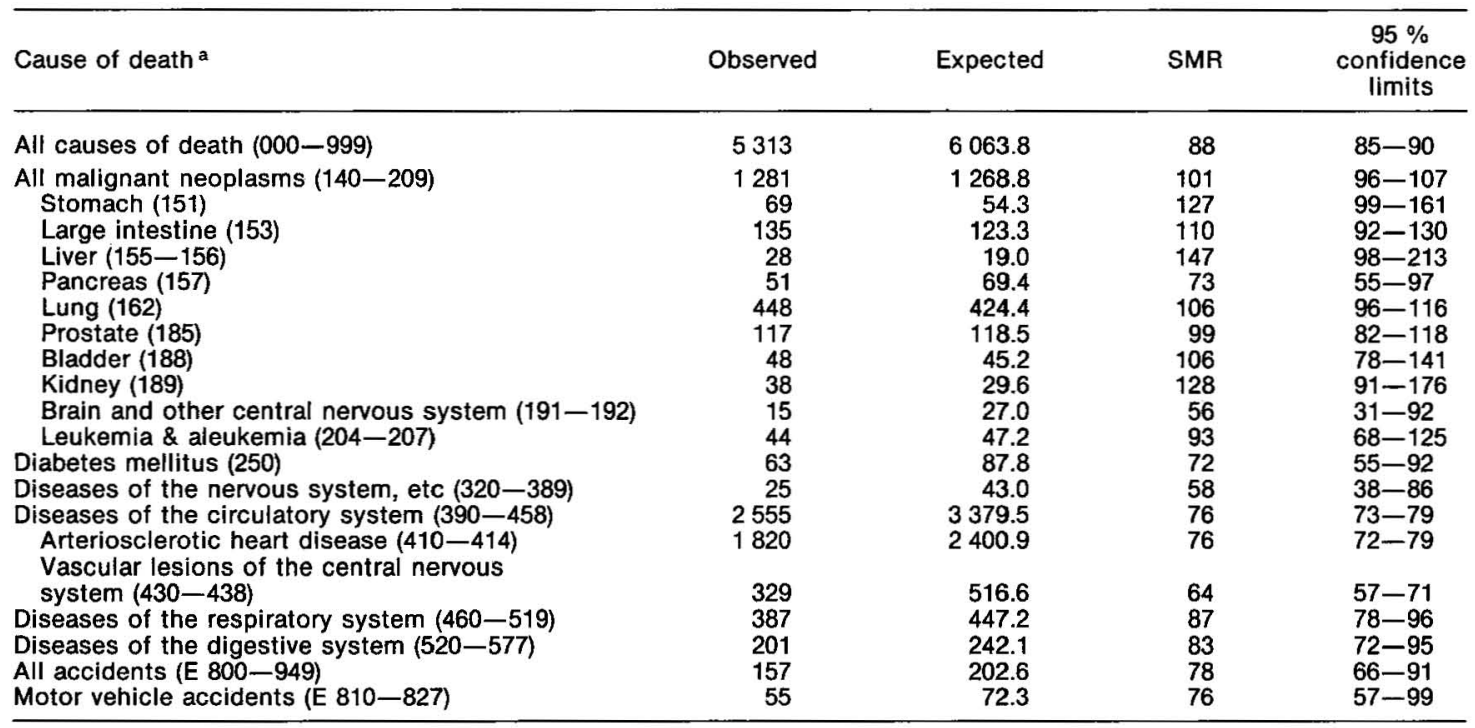

a According to the International Classification of Diseases Adapted (code 8).

Table 4. Standardized proportionate mortality ratios (PMR) for selected causes of death among the total study membership, 1975-1979.

\begin{tabular}{|c|c|c|c|c|}
\hline Cause of death ${ }^{a}$ & Observed & Expected & PMR & $\begin{array}{c}95 \% \\
\text { confidence } \\
\text { limits }\end{array}$ \\
\hline All malignant neoplasms $(140-209)$ & 1282 & 1142.2 & 112 & $107-118$ \\
\hline Stomach (151) & 69 & 48.0 & 144 & $114-182$ \\
\hline Large intestine (153) & 135 & 109.0 & 124 & $105-146$ \\
\hline Liver $(155-156)$ & 28 & 17.1 & 164 & $114-236$ \\
\hline Pancreas (157) & 51 & 62.6 & 81 & $62-107$ \\
\hline Lung (162) & 448 & 392.1 & 114 & $105-125$ \\
\hline Prostate (185) & 117 & 97.9 & 120 & $100-143$ \\
\hline Bladder (188) & 48 & 38.8 & 124 & $93-164$ \\
\hline Kidney (189) & 38 & 27.2 & 140 & $102-191$ \\
\hline Brain and other central nervous system (191-192) & 15 & 25.9 & 58 & $35-95$ \\
\hline Leukemla \& aleukemia (204-207) & 44 & 41.6 & 106 & $79-142$ \\
\hline Diabetes mellitus $(250)$ & 63 & 77.3 & 82 & $64-104$ \\
\hline Diseases of the nervous system, etc $(320-389)$ & 25 & 39.1 & 64 & $43-94$ \\
\hline Diseases of the circulatory system $(390-418)$ & 2555 & 2903.6 & 88 & $86-90$ \\
\hline Arteriosclerotic heart disease $(410-414)$ & 1820 & 2086.6 & 87 & $84-90$ \\
\hline Vascular lesions of the central nervous & & & & \\
\hline system $(430-438)$ & 329 & 423.2 & 78 & $70-86$ \\
\hline Diseases of the respiratory system $(460-519)$ & 387 & 382.0 & 101 & $92-111$ \\
\hline Diseases of the digestive system $(520-577)$ & 201 & 222.7 & 90 & $79-103$ \\
\hline All accidents (E 800-949) & 157 & 191.5 & 82 & $71-95$ \\
\hline Motor vehicle accidents (E 810-827) & 55 & 71.3 & 77 & $60-100$ \\
\hline
\end{tabular}

a According to the International Classification of Diseases Adapted (code 8).

three individuals were excluded from the analysis as their trade affiliation could not be determined. When members of mixed locals only were considered (table 5 ), the overall mortality was only slightly less than that of the US white male rate (SMR =93). Mortality from malignant neoplasms was somewhat higher than expected $(S M R=110)$. Two individual cancer sites were significantly elevated, cancer of the stomach $(S M R=136)$ and cancer of the lung $(S M R=118)$. The mortality ratio for circulatory diseases remained low $(S M R=79)$. Mortality from all accidents (SMR $=91$ ) and from motor vehicle accidents $(S M R=81)$ remained somewhat lower than expected.
The members of allied trade locals presented a considerably different mortality experience (table 6). Lower than expected mortality ratios were observed for all causes of death $(\mathrm{SMR}=75)$, all circulatory diseases $(\mathrm{SMR}=69)$, and all malignant neoplasms (SMR $=84)$. Most notably there was a statistically significant deficit of lung cancer $(\mathrm{SMR}=82)$ and leukemia $(\mathrm{SMR}=46)$ among these workers. The standardized mortality ratios for all respiratory disease, diseases of the digestive system, all accidents, and all motor vehicle accidents were low.

To investigate further the difference in mortality experience of members of mixed and specialty locals, in- 
Table 5. Standardized mortality ratios (SMR) for selected causes of death for members of mixed locals, $1975-1979$.

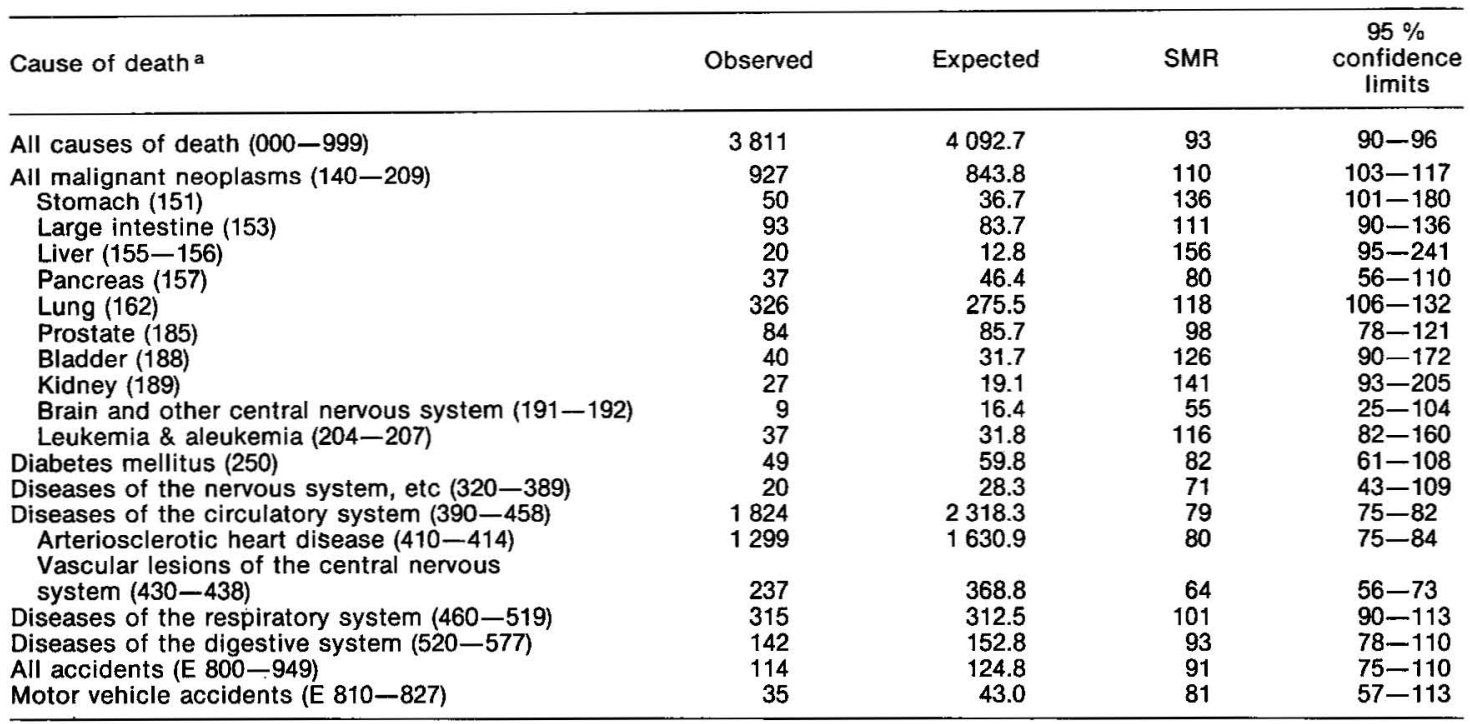

a According to the International Classification of Diseases Adapted (code 8).

Table 6. Standardized mortality ratios (SMR) for selected causes of death for members of specialty locals, $1975-1979$.

\begin{tabular}{|c|c|c|c|c|}
\hline Cause of death ${ }^{a}$ & Observed & Expected & SMR & $\begin{array}{c}95 \% \\
\text { confidence } \\
\text { limits }\end{array}$ \\
\hline All causes of death $(000-999)$ & 1480 & 1961.6 & 75 & $72-79$ \\
\hline $\begin{array}{l}\text { All malignant neoplasms (140-209) } \\
\text { Stomach (151) } \\
\text { Large intestine (153) } \\
\text { Liver (155-156) } \\
\text { Pancreas (157) } \\
\text { Lung (162) } \\
\text { Prostate (185) } \\
\text { Bladder (188) } \\
\text { Kidney (189) } \\
\text { Brain and other central nervous system (191-192) } \\
\text { Leukemia \& aleukemia (204-207) } \\
\text { Diabetes mellitus (250) } \\
\text { Diseases of the nervous system, etc (320-389) } \\
\text { Diseases of the circulatory system (390-458) } \\
\text { Arteriosclerotic heart disease (410-414) } \\
\text { Vascular lesions of the central nervous }\end{array}$ & $\begin{array}{r}354 \\
19 \\
42 \\
8 \\
14 \\
122 \\
33 \\
8 \\
11 \\
6 \\
7 \\
14 \\
5 \\
728 \\
519\end{array}$ & $\begin{array}{r}423.8 \\
17.5 \\
39.4 \\
6.2 \\
23.0 \\
148.7 \\
32.5 \\
13.4 \\
10.5 \\
10.6 \\
15.3 \\
27.9 \\
14.7 \\
1054.8 \\
765.9\end{array}$ & $\begin{array}{r}84 \\
108 \\
107 \\
129 \\
61 \\
82 \\
102 \\
60 \\
105 \\
56 \\
46 \\
50 \\
34 \\
69 \\
68\end{array}$ & $\begin{array}{l}75-93 \\
65-169 \\
77-144 \\
56-255 \\
33-102 \\
68-98 \\
70-143 \\
26-117 \\
52-188 \\
21-123 \\
18-94 \\
27-84 \\
11-79 \\
64-74 \\
62-74\end{array}$ \\
\hline $\begin{array}{l}\text { system }(430-438) \\
\text { Diseases of the respiratory system }(460-519) \\
\text { Diseases of the digestive system }(520-577) \\
\text { All accidents (E } 800-949) \\
\text { Motor vehicle accidents (E } 810-827)\end{array}$ & $\begin{array}{l}91 \\
72 \\
59 \\
43 \\
20\end{array}$ & $\begin{array}{r}146.4 \\
133.8 \\
89.1 \\
77.6 \\
29.3\end{array}$ & $\begin{array}{l}62 \\
54 \\
66 \\
55 \\
68\end{array}$ & $\begin{array}{l}50-76 \\
42-68 \\
50-85 \\
40-75 \\
42-105\end{array}$ \\
\hline
\end{tabular}

a According to the International Classification of Diseases Adapted.(code 8).

ternal comparisons were made using the method of Breslow \& Day (1). The entire study population was utilized as the standard for the calculation of the expected deaths for the two subpopulations. Using the total population as the standard also eliminated possible biases due to differences between the cohort and US white males such as racial, demographic, and personal characteristics.

When the mortality experience of members of mixed locals was compared to that of specialty locals, the standardized mortality ratio for all causes of death was 106 for mixed locals and 88 for specialty locals (p < 0.001) (table 7). For all malignant neoplasms, the differences were slightly greater with a standardized mortality ratio of 109 for members of mixed locals and 83 for specialty locals $(p<0.001)$. These results were very similar to the standardized mortality ratios calculated with the use of US white male rates. There was an even greater difference in mortality from cancer of the lung, with a standardized mortality ratio of 113 for mixed locals and 77 for specialty locals $(p<0.001)$. Differences were also observed between the two groups in terms of mortality from cancer of the bladder $(\mathrm{p}<0.05)$ and leukemia $(\mathrm{p}<0.05)$. 
Table 7. Standardized mortality ratios (SMR) for members of mixed versus specialty locals.

\begin{tabular}{lccc}
\hline \multirow{2}{*}{ Cause of death ${ }^{\text {a }}$} & \multicolumn{2}{c}{ SMR } & p-Value \\
\cline { 4 - 4 } & Mixed & Speciality & $0.001^{*}$ \\
All causes of death (000-999) & 106 & 88 & $0.001^{*}$ \\
All malignant neoplasms (140-209) & 109 & 83 & $0.001^{*}$ \\
Lung cancer (162) & 113 & 77 & 0.580 \\
Stomach cancer (151) & 105 & 90 & 0.950 \\
Large intestine cancer (153) & 100 & 101 & 0.184 \\
Rectal cancer (154) & 117 & 65 & 0.667 \\
Liver cancer (primary) (155) & 107 & 85 & 0.893 \\
Prostate cancer (185) & 101 & 98 & $0.022^{*}$ \\
Bladder cancer (188) & 122 & 53 & 0.484 \\
Kidney cancer (189) & 108 & 84 & 0.802 \\
Thyroid cancer (193) & 85 & 122 & $0.022^{*}$ \\
Leukemia \& aleukemia (204-207) & 123 & 51 & 24064 \\
\hline Persons & 32884 & 109229 & \\
Person-years & 147595 & & \\
\hline
\end{tabular}

a According to the International Classification of Diseases Adapted (code 8).

* Significant at $p<0.05$.

\section{Discussion}

Overall, the membership of both the mixed and specialty locals experienced a lower rate of mortality than did all US white males during 1975-1979. As many Union members were still employed, they may have been healthier than the entire US population. However, the study population included many retirees who may be either ill or well. With $20.7 \%$ of the study population aged 65 years and older, the proportion of elderly individuals in the study cohort was similar to the age composition of the study states (17).

Analysis of the mortality experience of the membership of this union suggested that the painters and allied tradesmen presented a different mortality experience, particularly for malignant neoplasms. The overall mortality experience for members of the mixed locals was $93 \%$ of that of all US white males. The overall mortality of members of the specialty locals was much lower at $75 \%$. The cause of the difference in mortality experience is not clear.

The elevated lung cancer mortality among members of the mixed locals was observed both when comparisons were made with US white males and with allied trade members. This finding is consistent with the results of a case-referent study of this population in which occupational data were collected by questionnaire (15).

Among members of the mixed locals there was an elevation in leukemia and aleukemia, whereas the mortality from these two diseases was lower among the specialty trade locals. Mortality from cancer of the stomach appeared to be slightly elevated among members of both the mixed $(\mathrm{SMR}=136)$ and specialty $(\mathrm{SMR}=108)$ locals, although statistically significant only for the former. As ethnicity information was not available, it was not possible to assess the impact of this factor on the stomach cancer mortality of the Union members. The standardized mortality ratio for bladder cancer was not significantly elevated among members of the mixed locals in comparison to that of US white males. The internal comparisons suggest that the differences in mortality ratios for bladder cancer of members of the mixed and specialty locals might warrant further study.

Paint technology is a rapidly changing field. The possible components of paint formulations are almost limitless. Continued assessment of the population will be required to determine whether the removal of asbestos from spackling compound and changes in paint technology over time have altered the risks experienced by these workers. Construction painters use a wide variety of paint formulations. Additional studies of painters in other industries, whose work requires the use of fewer types of paints, should be conducted in an attempt to identify specific paints and painting activities which may be associated with increased cancer risks.

\section{Acknowledgments}

This research was supported by the National Institute for Occupational Safety and Health (NIOSH), contract number 210-77-0096.

NIOSH project officers for various components of this study were Ms M Haring-Sweeney, Mr S Leffingwell, Mr R Roscoe, and Mr D Zaebst.

\section{References}

1. Breslow NE, Day NE. Indirect standardization and multiplicative model for rates with reference to the age adjustment of cancer incidence and relative frequency data. J Chronic Dis 28 (1975) 289-303.

2. Chiazze L Jr, Ference L, Wolf PH. Mortality among automobile assembly workers: Spray painters. J Occup Med 22 (1980) 520-526.

3. Dalager NA, Mason TJ, Fraumeni JF Jr, Hoover R, Payne, WW. Cancer mortality among workers exposed to zinc chromate paint. J Occup Med 22 (1980) 25-29. 
4. Davis JM. Lung cancer mortality of workers making chrome pigments. Lancet 1 (1978) 384.

5. Dunn JE, Linden G, Breslow L. Lung cancer mortality experience of men in certain occupations in California. Am J Public Health 50 (1960) 1475-1487.

6. Dunn JE, Weir JM. Cancer experience of several occupational groups followed prospectively. Am J Public Health 55 (1965) 1367-1375.

7. Guralnick L. Mortality by occupation and cause of death among men 20 to 64 years of age: United States 1950. US Public Health Service, Washington, DC 1963. (Vital statistics-special report 53,3 ).

8. Langard S, Norseth T. A cohort study of bronchial carcinomas in workers producing chromate pigments. $\mathrm{Br}$ $J$ Ind Med 32 (1975) 62-65.

9. Milham S Jr. Occupational mortality in Washington state 1950-71. US Public Health Service, Washington, DC 1967.

10. Monson RR. Analysis of relative survival and proportional mortality. Comput Biomed Res 7 (1974) 325-332.

11. Morgan RW, Claxton KW, Kaplan SD, Parsons JA, Wong $\mathrm{O}$. Mortality of paint and coatings industry workers: A follow up study. J Occup Med 27 (1985) 377378.

12. Morgan RW, Kaplan SD, Gaffey WR. A general mortality study of production workers in the paint and coatings manufacturing industry: A preliminary report. J Occup Med 23 (1981) 13-21.

13. Registrar General. Decennial supplement for England and Wales: 1951 occupational mortality Part II. Volume 1. Her Majesty's Stationery Office, London 1958.
14. Registrar General. Decennial supplement for England and Wales: Occupational mortality 1970-72. Her Majesty's Stationery Office, London 1976.

15. Stockwell HG, Matanoski GM. A case-control study of lung cancer in painters. J Occup Med 27 (1985) 125126.

16. US Bureau of the Census. Census of population: 1970 , occupational characteristics report PC(2)-7A. Washington, DC 1973.

17. US Bureau of the Census. Statistical abstract of the United States. 103rd edition. Washington, DC 1982.

18. US Department of Health, Education and Welfare. Occupational characteristics of disabled workers by disabling condition: Disability insurance benefits awards made in 1959-62 to men under age 65. Washington, DC 1967. (Public Health Service publication 1531).

19. Viadana E, Bross IDJ. Leukemia and occupations. Prev Med 1 (1972) 513-521.

20. Viadana E, Bross IDJ, Houten L. Cancer experience of men exposed to inhalation of chemicals or to combustion products. J Occup Med 18 (1976) 787-792.

21. Williams RR, Stegens NL, Goldsmith JR. Associations of cancer site and type with occupation and industry from the third national cancer survey interview. J Natl Cancer Inst 59 (1977) 1147-1185.

Received for publication: 29 July 1985 